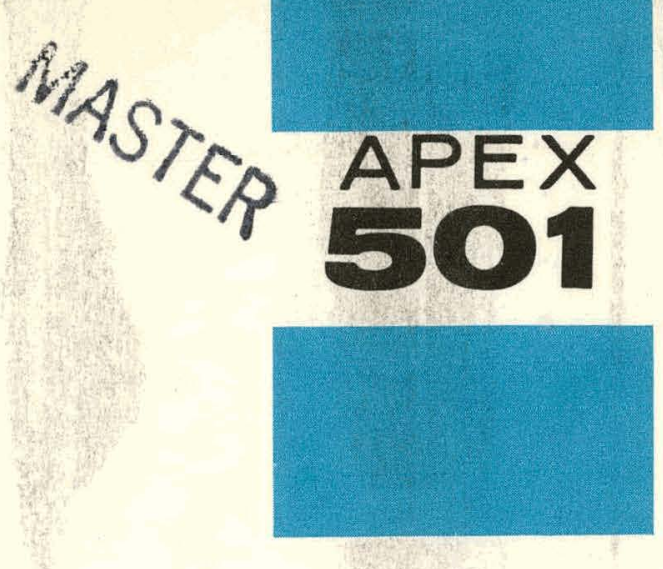

\title{
A HIGH IMPEDANCE INPUT CIRCUIT USING GERMANIUM TRANSISTORS
}

\author{
J. J. Baum
}

\section{GENERAL ELECTRIC} ATOMIC PRODUCTS DIVISION 


\section{DISCLAIMER}

This report was prepared as an account of work sponsored by an agency of the United States Government. Neither the United States Government nor any agency Thereof, nor any of their employees, makes any warranty, express or implied, or assumes any legal liability or responsibility for the accuracy, completeness, or usefulness of any information, apparatus, product, or process disclosed, or represents that its use would not infringe privately owned rights. Reference herein to any specific commercial product, process, or service by trade name, trademark, manufacturer, or otherwise does not necessarily constitute or imply its endorsement, recommendation, or favoring by the United States Government or any agency thereof. The views and opinions of authors expressed herein do not necessarily state or reflect those of the United States Government or any agency thereof. 


\section{DISCLAIMER}

Portions of this document may be illegible in electronic image products. Images are produced from the best available original document. 


\section{LEGAL NOTICE}

This report was prepared as an account of Government sponsored work. Neither the United States, nor the Commission, nor the Air Force, nor any person acting on behalf of the Commission or the Air Force:

A. Makes any warranty or representation, express or implied, with respent to the accuracy, completeness, or usefulness of the information contained in this report, or that the use of any information, apparatus, methud, or prosess disclosed in this report may not infringe privately owned rights; or

B. Assumes any liabilities with respect to the use of, or for damages resulting from the use of any information, apparatus, method, or process disclosed in this report.

As used in the above "person acting on behalf of the Commission or Air Force" includes any employee or contractor of the Commission or Air Force to the extent that such employee or contractor preparas, handles, or distributes, or provides access to, any information pursuant to his employment or contract with the Commission or Air Force.

Printed in IISA. Price 75 cents. Available from the

Office of Technical Services

U.S. Department of Commerce

Washington 25, D. C. 
AFEX - 501

UC-37 Instruments

TID -4500 (14th Ẽd.)

\title{
A HIGH IMPEDANCE INPUT CIRCUIT USING GERMANIUM TRANSISTORS
}

\author{
J. J. Baum \\ Nuclear Development Laboratories \\ Sub-Section \\ September 1958 \\ United States Air Force \\ United States Atomic Energy Commission \\ Contract No. AF 33(600)-38062 \\ Contract No. AT (11-1)-171

\section{GENERAL ELECTRIC \\ ATOMIC PRODUCTS DIVISION AIRCRAFT NUCLEAR PROPULSION DEPARTMENT CINCINANAII 15, UHIO} \\ Publishod by \\ Technicol Publications Sub-Section \\ June 1954
}


THIS PAGE

\section{WAS INTENTIONALLY \\ LEFT BLANK}




\section{Abstract}

$\Lambda$ bootctrapped-emitter-follower circuit that arhieves an input impedance greater than $10^{7} \mathrm{ohms}$ with germanium transistors is described. The circuit is analyzed and compared with a single emitter follower and a super-alphaconnected emitter follower for input impedance characteristics. 


\section{THIS PAGE}

\section{WAS INTENTIONALLY \\ LEFT BLANK}




\section{Introduction}

Several important appliçations exist for low-level, high-input-impedance amplifiers, particularly in the field of nuclear instrumentation. The development of an alternatingcurrent ionization chamber, for example, required a 500-cycle amplifier with a noise level below 10-17 watts and an input impedance of at least a few megohms. In this particular application the smaller size, weight, and power requirements, and negligible microphonics of a transistorized circuit seemed to indicate the use of transistors. 
THIS PAGE

WAS INTENTIONALLY

LEFT BLANK 


\section{Input Circuit}

Of the three transistor configurations that can be used to provide a power gain in exiess of unity, the common-collector (emitter follower) connection gives the highest input impedance for any given load. This circuit, shown in Figure 1, has an input resistance:

$$
\mathrm{R}_{\mathrm{i}}=\frac{\mathrm{h}_{\mathrm{i}}+\Delta^{\mathrm{h}} \mathrm{R}_{\mathrm{L}}}{1+\mathrm{h}_{\mathrm{o}} \mathrm{R}_{\mathrm{L}}}
$$

where the $h$ 's are the common-collector hybrid parameters, and $\Delta^{h}=h_{i} h_{0}-h_{r} h_{f}$. In the case of the $2 \mathrm{~N} 369$, a typical good germanium transistor,

$$
\begin{aligned}
& \mathrm{h}_{\mathrm{i}}=1670 \text { ohms } \\
& \mathrm{h}_{\mathrm{o}}=28 \times 10^{-6} \text { mho } \\
& \mathrm{h}_{\mathrm{r}}=1-3.33 \times 10^{-6} \\
& \mathrm{~h}_{\mathrm{f}}=-56
\end{aligned}
$$

and the maximum value of input impedance obtainable, even with very large load resistance, is about 2 megohms. Furthermore, since a bias resistor of about the same order of magnitude appears essentially in shunt with this impedance, it is not surprising that transistor amplifiers with input impedances greater than 1 megohm are uncommon.

Although a single transistor stage is thus limited in its input impedance, it is possible to arrange two or more transistors into a composite device, the characteristics of which are superior to those of the individual components. One such circuit, called a superalpha connection, is shown in Figure 2.

Analysis of this configuration shows that the super-alpha-connected pair can be represented as a single compusite transistor with greatly improved characteristics. Such a connection using two of the 2 N 369 germanium transistors described would have the following common-collector parameters:

$$
\begin{aligned}
& \mathrm{h}_{\mathrm{i}}=97000 \mathrm{ohms} \\
& \mathrm{h}_{\mathrm{f}}=-3250 \\
& \mathrm{~h}_{\mathrm{r}}=1 \\
& \mathrm{~h}_{\mathrm{o}}=1.62 \times 10^{-3} \text { mho }
\end{aligned}
$$

These values, when inserted in equation(1), show that although the upper limit of input impedance is still about 2 megohms, it is not as strong a function of load resistance as in the case of the single emitter follower. The input impedance for the super-alpha connection exceeds 100,000 ohms even for very small load resistances. Figure 3 shows this result graphically and compares it with the input impedance of a single emitter follower. It must be remembered, of course, that these impedances are in practice shunted by a base-to-collector bias resistor that reduces the actual impedances to still lower values. 


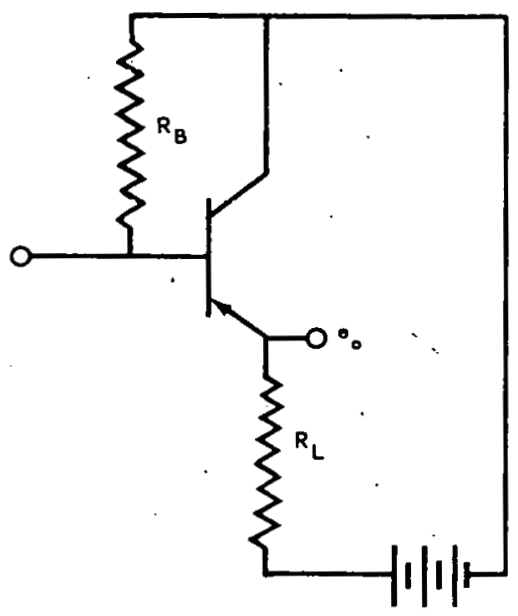

Fig. 1-Common-collector connection

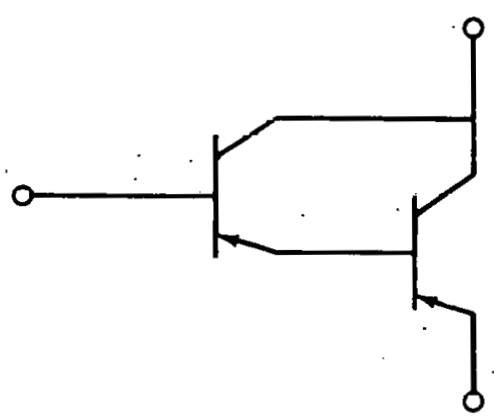

Fig. 2-A super-alpha connection 


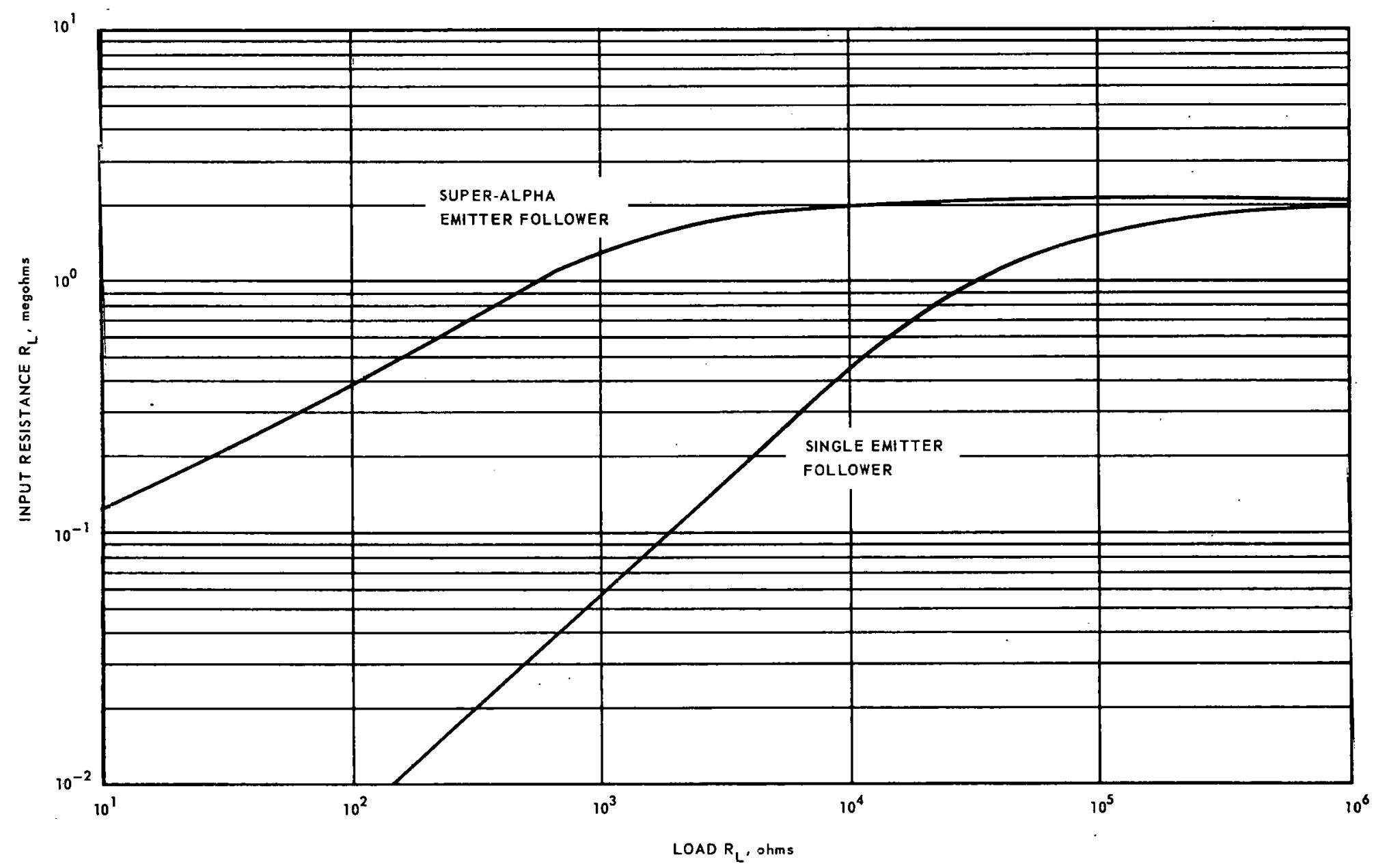

Fig. 3-Comparison of super-alpha connection and single emitter follower 
A qualitative examination of the emitter follower of Figure 1 indicates that the input impedance can be increased if both the emitter signal current and the signal current flowing through the bias resistor can be reduced. Since the emitter voltage follows the base voltage closely, the common terminal (collector) must also be forced to follow the variations in base voltage. Circuits to achieve this result have been developed and are known as bootstrapped emitter followers, an example of which is shown in Figure 4.

Other arrangements are possible, including the use of more than two transistors in order to supply more power to the bootstrap voltage. Input impedances as high as 1000 megohms have been obtained using three silicon transistors in a circuit employing bootstrapped operation of an emitter follower. Since the requirements were more modest, two 2N369 germanium transistors were used in the circuit of Figure 4 with:

$$
\begin{aligned}
& R_{1}=47 \mathrm{~K} \\
& R_{2}=14 \mathrm{~K} \\
& R_{3}=5 \mathrm{meg}
\end{aligned}
$$

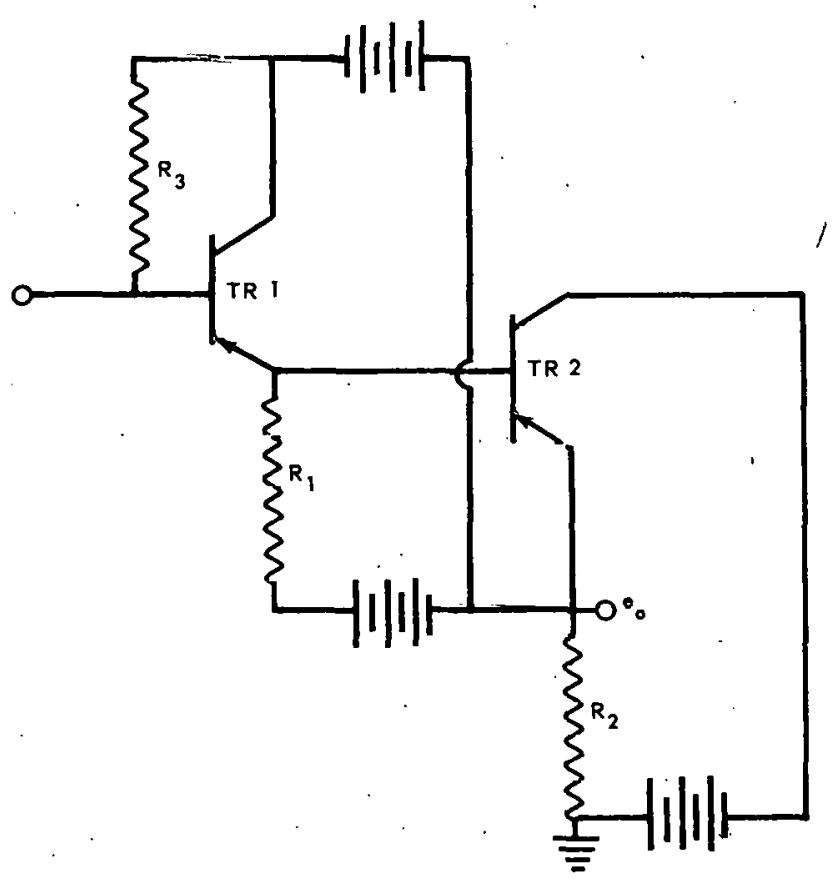

Fig. 4-Bootslrapped-emitter-follower circuit 


\section{Circuit Analysis}

The common-collector-equivalent circuit of Figure 5 can be used to build up the compusile equivalent circuit of figure 6 that represents the electrical characteristics of the bootstrapped-emitter-follower circuit of Figure 4 in the low and middle frequencies.

Summing the currents at the output terminal. node, we obtain:

$$
\begin{aligned}
O=v_{0} & \left(\frac{1}{R_{L}}+\frac{1}{R_{2}}+h_{0}\right)+h_{f} i_{i} 2-\left[v_{01}\left(\frac{1}{R_{1}}+h_{0}\right)+h_{f} i_{i}\right] \\
& +\left(v_{0}-v_{i}\right) \frac{1}{R_{3}}+\left(v_{o}+h_{r} v_{01}-v_{i}\right) \frac{1}{h_{i}}
\end{aligned}
$$

and since

$$
i_{i 2}=-\left[v_{01}\left(\frac{1}{R 1}+h_{0}\right)+h_{f}^{i} i_{i}\right]
$$

equation (2) can be rewritten:

$$
\begin{aligned}
& V_{0}\left(\frac{1}{R_{L}}+\frac{1}{R_{2}}+h_{0}+\frac{1}{R_{3}}+\frac{1}{h_{i}}\right)-V_{i}\left(\frac{1}{R_{3}}+\frac{1}{h_{i}}\right)+v_{01}\left(\frac{h_{0}}{h_{i}}-\frac{1}{R_{1}}-h_{o}-\frac{h_{f}}{R_{1}}-h_{f} h_{0}\right) \\
&-i_{i}\left(h_{f}^{2}-h_{f}\right)=0 .
\end{aligned}
$$

Summing currents at the input terminal node results in:

$$
i_{i}=I_{i}+\left(V_{0}-V_{i}\right) \frac{1}{R_{3}}
$$

so that

$$
\begin{gathered}
v_{0}\left[\frac{1}{R_{L}}+\frac{1}{R_{2}}+h_{o}+\frac{1}{R_{3}}+\frac{1}{h_{i}}-\frac{1}{R_{3}}\left(h_{f}^{2}+h_{f}\right)\right]+V_{i}\left[\frac{1}{R_{3}}\left(h_{f}^{2}+h_{f}\right)-\frac{1}{R_{3}}-\frac{1}{h_{i}}\right] \\
+v_{01}\left[\frac{h_{0}}{h_{i}}-\frac{1}{R_{1}}-h_{o}-\frac{h_{f}}{R_{1}}-h_{f} h_{0}\right]-I_{i}\left(h_{f}^{2}+h_{f}\right)=0
\end{gathered}
$$

From the loop containing the current generator $h_{f} h_{i 2}$ and the voltage generator $h_{r} V_{0}$,

$$
\mathrm{v}_{\mathrm{o}}+\mathrm{v}_{01}=\mathrm{h}_{\mathrm{r}} \mathrm{v}_{\mathrm{o}}+\mathrm{i}_{\mathrm{i} 2} \frac{1}{\mathrm{~h}_{\mathrm{i}}}
$$

can be obtained, which, combined with equations (3) and (5), yields: 


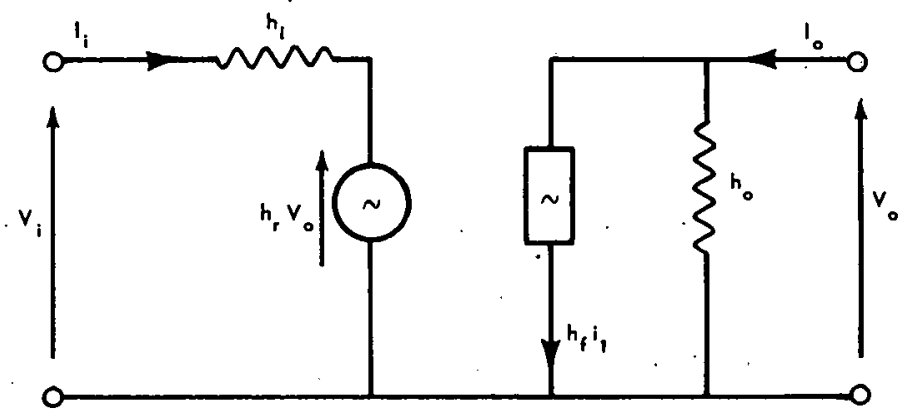

Fig. 5-Common-collector equivalent circuit

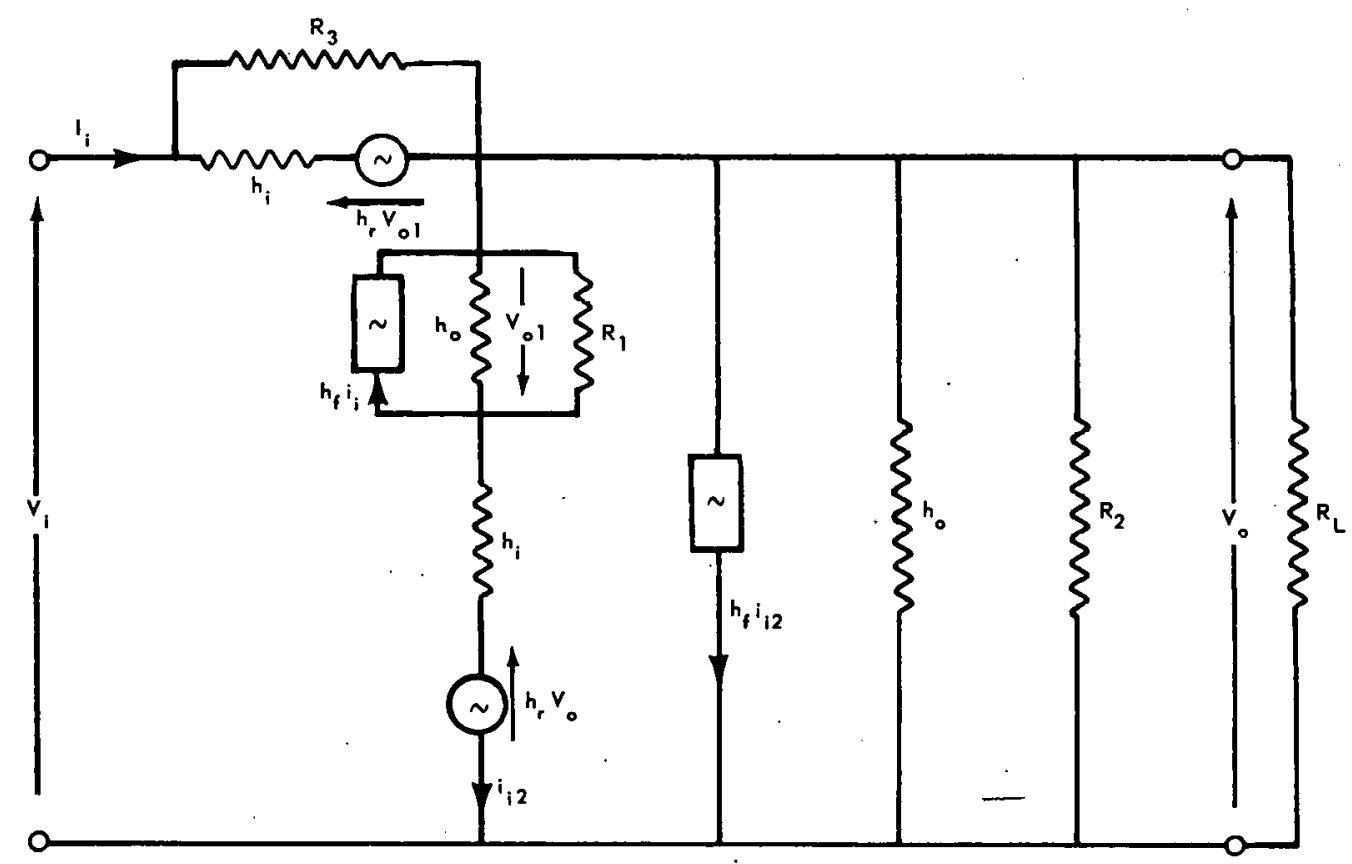

Fig. 6-Composite circuit that represents the electrical characteristics of the bootstrapped-omitter-follower circuit 


$$
\mathrm{v}_{01}=\frac{-\mathrm{V}_{\mathrm{o}}\left(\mathrm{h}_{\mathrm{i}}+\mathrm{h}_{\mathrm{i}} \mathrm{h}_{\mathrm{r}}+\frac{\mathrm{h}_{\mathrm{f}}}{\mathrm{R}_{3}}\right)-\mathrm{V}_{\mathrm{i}} \frac{\mathrm{h}_{\mathrm{f}}}{\mathrm{R}_{3}}-\mathrm{I}_{\mathrm{i}} \mathrm{h}_{\mathrm{f}}}{\mathrm{h}_{\mathrm{i}}+\frac{1}{\mathrm{R}_{1}}+\mathrm{h}_{\mathrm{o}}}
$$

Substituting equation (8) for $\mathrm{v}_{01}$ in equation (6), and letting:

$$
\begin{aligned}
& A=\frac{1}{R_{L}}+\frac{1}{R_{2}}+h_{0}+\frac{1}{R_{3}}+\frac{1}{h_{i}}-\frac{D}{R_{3}} \\
& B=\frac{D}{R_{3}}-\frac{1}{R_{3}}-\frac{1}{h_{i}} \\
& C=\frac{h_{0}}{h_{i}}-\frac{1}{R_{1}}-h_{0}-\frac{h_{f}}{R_{1}}-h_{f} h_{0} \\
& D=h_{f}\left(h_{f}+1\right)
\end{aligned}
$$

we find that:

$$
\begin{gathered}
0=v_{0}\left[A-\frac{\left(h_{i}-h_{r} h_{i}+\frac{h_{f}}{R_{3}}\right)}{\left(h_{i}+\frac{1}{R_{1}}+h_{o}\right)} C\right]+V_{i}\left[B-\frac{h_{f} C}{R_{3}\left(h_{i}+\frac{1}{R_{1}}+h_{o}\right)}\right] \\
-I_{i}\left[D+\frac{h_{f} C}{h_{i}+\frac{1}{R_{1}}+h_{0}}\right]
\end{gathered}
$$

A summation of voltages about the loop containing the input voltage and the two voltage generators yields:

$$
v_{i}=i_{i} h_{i}+h_{r} v_{01}-v_{01}+i_{i 2} h_{i}+h_{r} v_{0}
$$

which, by application of equations (3), (5), and (8) and the following definitions:

$$
\begin{aligned}
& E=h_{r}-1-\frac{h_{i}}{R_{1}}-h_{0} h_{i} \\
& F=h_{i}-h_{f} h_{i} \\
& G=h_{i}-h_{i} h_{r}+\frac{h_{f}}{R_{3}} \\
& H=h_{1}+\frac{1}{R_{1}}+h_{0},
\end{aligned}
$$

becomes:

$$
V_{o}\left[\frac{F}{R_{3}}+h_{r}-\frac{G E}{H}\right]-V_{i}\left(1+\frac{F}{R_{3}}+\frac{h_{f} E}{R_{3} H}\right)+I_{i}\left(F-\frac{h_{f} E}{H}\right)=0
$$

Application of equations (15), (16), (17), and (18) to equation (13) yields:

$$
V_{o}\left(A-\frac{G C}{H}\right)+V_{i}\left(B-\frac{h_{f} C}{R_{3} H}\right)-I_{i}\left(D+\frac{h_{f} C}{H}\right)=0
$$




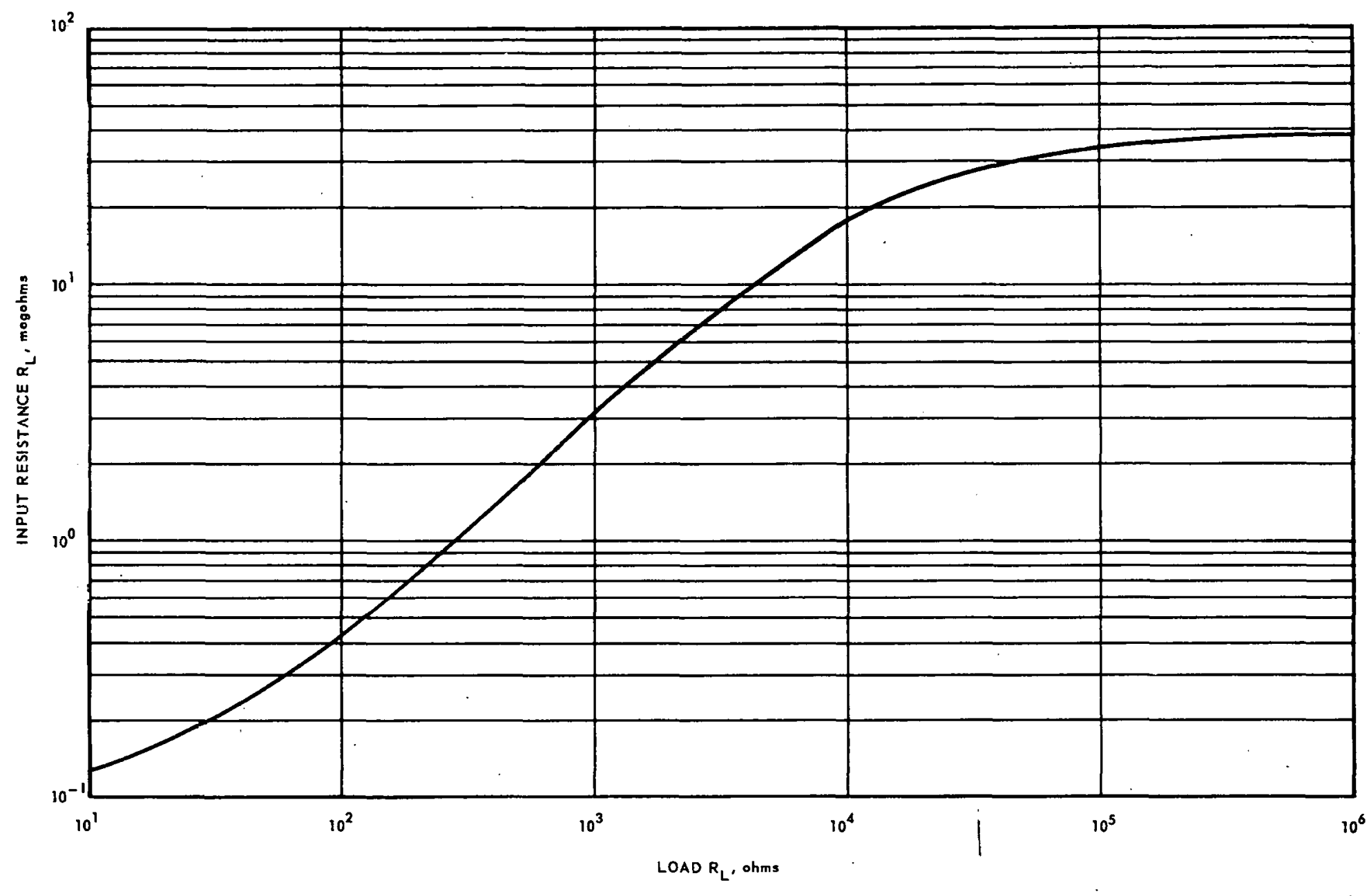

Fig. 7-Input resistance versus load - bootstrapped emitter follower 
It is now possible to eliminate $V_{0}$ from equations (19) and (20) to obtain:

$$
\begin{gathered}
0=I_{i}\left[\frac{\left(D+\frac{h_{f} C}{H}\right)}{\left(A-\frac{G C}{H}\right)}\left(\frac{F}{R_{3}}+h_{r}-\frac{G E}{H}\right)+\left(F-\frac{h_{f} E}{H}\right)\right]-V_{i}\left[\frac{\left(B-\frac{h_{f} C}{R_{3} H}\right)}{\left(A-\frac{G C}{H}\right)}\left(\frac{F}{R_{3}}+h_{r}-\frac{G E}{H}\right)\right. \\
\left.+\left(1+\frac{F}{R_{3}}+\frac{h_{f} E}{H_{R_{3}}}\right)\right]
\end{gathered}
$$

from which one can obtain the input impedance $\mathrm{Z}_{\mathbf{i}}$ :

$$
Z_{i}=\frac{V_{i}}{I_{i}}=\frac{\left(D+\frac{h_{f} C}{H}\right)\left(\frac{F}{R_{3}}+h_{r}-\frac{G E}{H}\right)+\left(F-\frac{h_{f} E}{H}\right)\left(A-\frac{G C}{H}\right)}{\left(B-\frac{h_{f} C}{R_{3} H}\right)\left(\frac{F}{R_{3}}+h_{r}-\frac{G E}{H}\right)+\left(1+\frac{F}{R_{3}}+\frac{h_{f} E}{H R_{3}}\right)\left(A-\frac{G C}{H}\right)}
$$

It would be possible at this point to replace the symbols $\mathrm{A}, \mathrm{B}, \mathrm{C}, \ldots, \mathrm{H}$ by their defined equivalents, and a cumbersome expression that might then simplify or at least be subject to simplifying assumptions would result. The primary concern, however, is the input impedance of the circuit of Figure 4 using two 2 N369 transistors and the experimentally adjusted values of the various circuit elements. The input impedance as a function only of load resistance $R_{L}$ is found by substituting these values in equation (22):

$$
\begin{aligned}
& \mathrm{h}_{\mathrm{i}}=1670 \mathrm{ohms} \\
& \mathrm{h}_{\mathrm{r}}=1-3.33 \times 10^{-6} \\
& \mathrm{~h}_{\mathrm{f}}=-56 \\
& \mathrm{~h}_{\mathrm{o}}=28 \times 10^{-6} \mathrm{mho} \\
& \mathrm{R}_{1}=47 \mathrm{~K} \\
& \mathrm{R}_{2}=14 \mathrm{~K} \\
& \mathrm{R}_{3}=5 \mathrm{meg}
\end{aligned}
$$

The evaluation of equation (22) then yields

$$
Z_{i}=\frac{95,200+3460 R_{L}}{1.02+92 \times 10^{-6} R_{L}}
$$

It is interesting to note that this equation is of the same form as the expression for the input impedance of a simple emitter follower as defined in equation (1). Effectively, what has been obtained is a transistor with the following common-collector parameters:

$$
\begin{aligned}
& h_{i}=95200 \\
& h_{r}=1 \\
& h_{f}=-3460 \\
& h_{u}=92 \times 1 n^{-6}
\end{aligned}
$$

Figure 7 is a graphical presentation of equation (23) and shows that an input impedance of 34 megohms should be obtainable in this circuit with a load of 0.1 megohm such as can be ublained with a simple emitter follower in the succeeding stage. 
THIS PAGE

WAS INTENTIONALLY

LEFT BLANK 


\section{Laboratory Performance}

The bootstrapped emitter follower was built in breadboard form and connected into the test rircuit of Figure 8.

With $R_{L}=14000$ ohms, the input impedance of the bootstrapped circuit was measured and found to be 18 megohms, in close agreement with the calculated curve of Figure 7 . The voltage gain was 0.98 from 20 to 20,000 cycles, falling off above this frequency to a 3-decibel point somewhat in excess of 200 kilocycles. The output impedance was 1100 ohms. With the circuit suitably shielded and the input shunted by a 0.5 megohm resistor, the narrow band ( 480 to 520 cycles) noise level was reduced to as low as 2 microvolts by the selection of the two least noisy transistors from the twelve on hand. This indicates a transistor noise figure of 12 decibels compared to the 7 decibels claimed by the manufacturer, but some increase is to be expected in view of the high value of input resistance and the frequency (500 cycles) used.

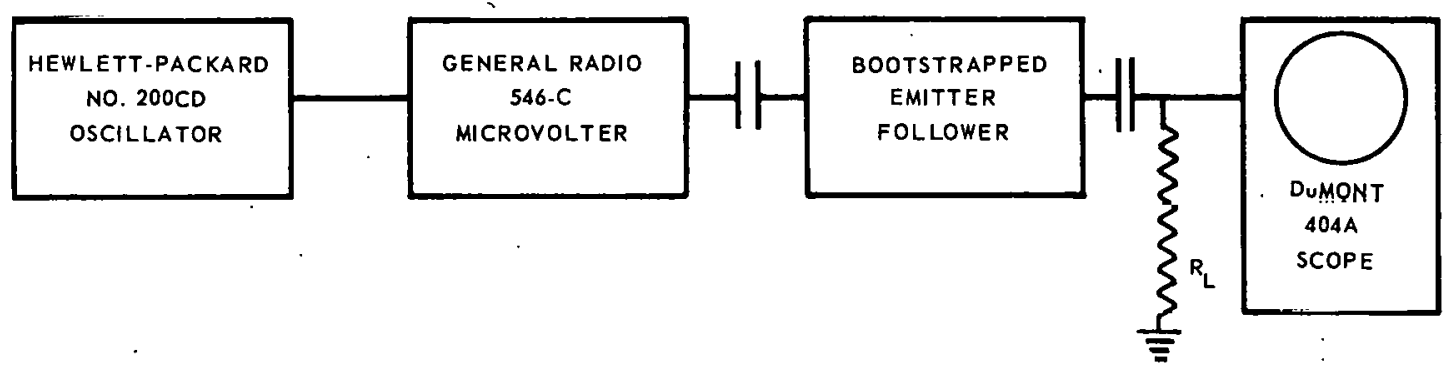

Fig. 8-Test circuit using bootstrapped emitter follower 
THIS PAGE

\section{WAS INTENTIONALLY LEFT BLANK}




\section{Conclusions}

The bootstrapped emitter follower performed essentially as expected from the results of the analysis and shows that transistors can be used to achieve high input impedainces usually obtained with vacuum tubes. The circuit is presently being used as the input stage in a low-level preamplifier that is used with an alternating-current ionization chamber, presently being developed. The complete amplifier, shown schematically in Figure 9 , has a stable voltage gain of 1000 at-500 cycles and is filtered to give a 40 -decibel-peroctave drop on either side of this frequency. 


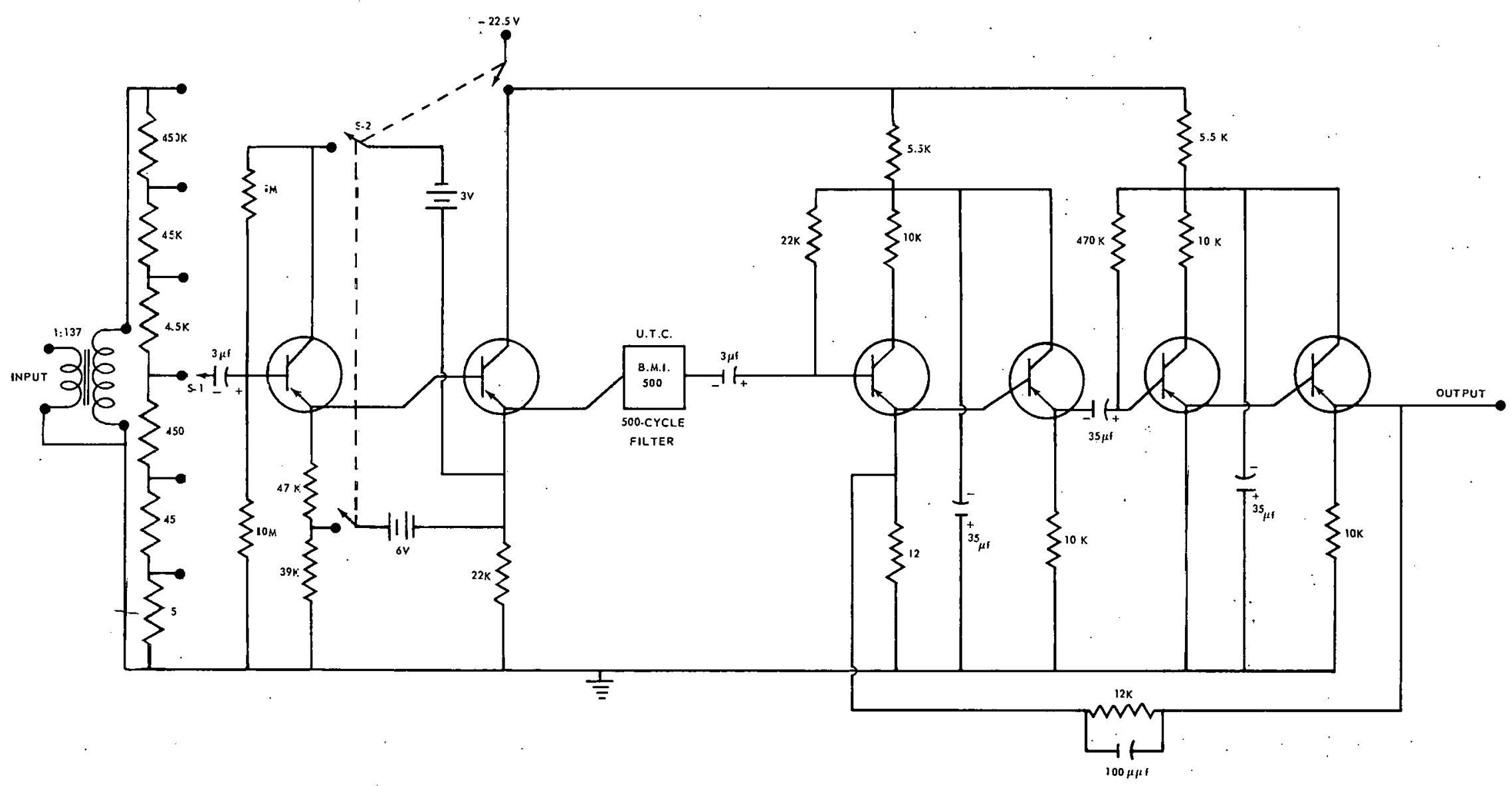

Fig. 9-500-cycle amplifier using the bootstrapped emitter follower as the infut stage 